\title{
The Design of Discharge Summary for Patients of Continuous Care
}

\author{
Laili Rahmatul Ilmi* \\ Medical Record and Health \\ Information \\ University of Jenderal Achmad Yani \\ Yogyakarta, Indonesia \\ lailiilmi@gmail.com \\ ORCID: 0000-0002-4402-8406
}

\author{
Ide Redika Sayekti \\ Medical Record and Health \\ Information \\ University of Jenderal Achmad Yani \\ Yogyakarta, Indonesia \\ 1317099ideredikas@gmail.com
}

\begin{abstract}
The use of information systems and technology in the health sector improves performance. A discharge summary is designed in an interface that can improve the quality of medical data documentation, efficiency, easy access to health information, support sustainable health decision-makers, and provide protection for patients, doctors, and health facilities as well as an exchange of information between health care providers. The objective of this study is to improve the quality of medical resume documentation as a comprehensive communication tool and support continuity of care. This research method is to design a web-based discharge summary portal interface display with a research design \& development method (R \& D) with a qualitative approach. The subject of this research is a doctor who has a discharge summary and medical record staff with in-depth interviews. The next stage is to design a web-based discharge summary portal referring to accreditation items and user input, then the design results are presented to doctors, medical record officers and managers. The manual discharge summary become a reference for designing the user interface for the patient discharge summary portal and there are several additional menus, namely; admin chat services, prayers when sick, SOAP, and hospital maps.
\end{abstract} of care

Keywords-design, interface, discharge summary, continuity

\section{INTRODUCTION}

The use of information systems and technology in the health sector improves performance. A discharge summary is designed in the utilization of health technology and information not only improves service performance but is more effective, provides easy data access, accelerates decision making (1). Several previous studies have explained that the use of technology and health information has an impact on the economy, social, speed of medical data exchange, communication tools (2). The paradigm shift in organizing paper to electronic medical records is certainly not an easy thing, it takes more effort to equalize perceptions, of course, this change is balanced with the readiness of all parties (3). The implementation of electronic medical records certainly requires a proper design according to user input, this is aimed at making it easy to fill in so that the data filled in is complete and accurate (4) (5).

The application of electronic medical records in integrated health services is of course very beneficial for doctors and other health workers to carry out communication and follow- up care (6). Researchers carried out initial identification of existing problems, PKU Muhammadiyah Bantul has implemented electronic medical records in outpatient services, but the utilization of discharge summaries has not been optimal. The researcher wants to optimize the use of electronic discharge summaries by designing a discharge summary portal through the stages of identifying initial requirements. At the identification stage, we conducted indepth interviews with doctors filling in the discharge summary, then the researchers designed the discharge summary portal, discussed the design results and implementation.

PKU Muhammadiyah Bantul Hospital uses a discharge summary to record patient health information so that services remain well integrated. In designing a web-based patient discharge summary portal, the authors obtained several things during the study:

\section{A. Identification of the patient's}

Discharge summary at PKU Muhammadiyah Bantul Hospital consists of manual and electronic discharge summary contained in the hospital's electronic medical records. For electronic discharge summary not yet accessible to all users. Only nurses and doctors in polyclinics can access electronic discharge summary. The doctor records the patient's health information into electronic medical records on the discharge summary menu with limited data elements that adjust the manual discharge summary.

\section{B. Requirement for User Interface Elements}

The data elements contained in the electronic discharge summary contained in the hospital information system adjust the manual discharge summary that the hospital has set according to accreditation standards. However, the discharge summary portal itself adds several menus to complete the information on the patient's discharge summary. The addition of these elements has been considered according to the data needs of discharge summary portal users.

\section{Designing discharge summary Portal User Interface}

The menus discharge summary will be made simple and attractive to make users comfortable when using the webbased portal. The dominant use of green and Islamic themes further adds to the characteristics of the PKU Muhammadiyah Bantul Hospital identity. Any data contained in the discharge 
summary portal will also be integrated with data in the hospital (Fig.1)

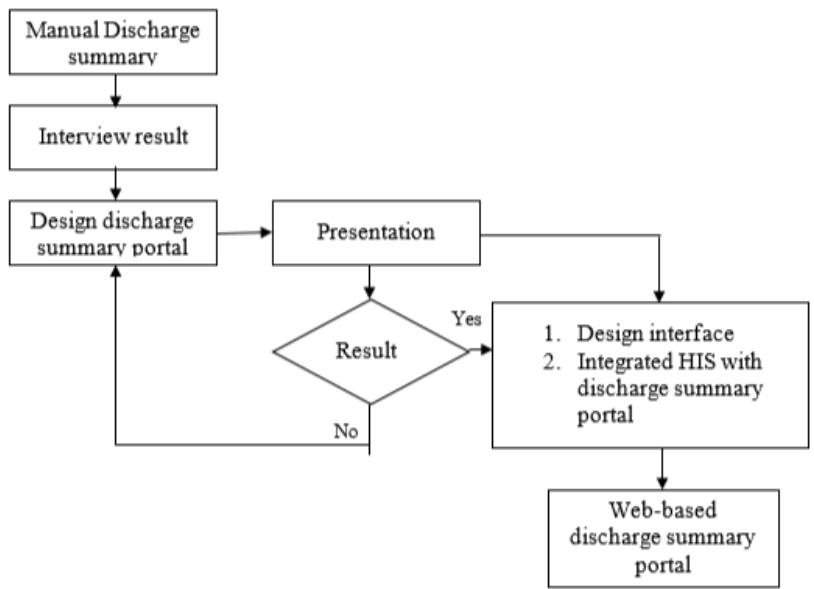

Fig. 1. Concept of design interface for discharge summary

\section{METHOD}

This was using a research \& development method (R\&D) research design with a qualitative approach. The initial identification stage of the researcher conducted interviews with 3 doctors who were willing to become informants and 3 medical record officers to find out the needs needed in designing the discharge summary portal. with a qualitative approach. The sample consisted who were selected after agree to be informants. Researchers used an interview guide to explore information on the need for electronic discharge summary design. After the interview, the researcher conducts the initial design as needed, then the stage 1 presentation is carried out. In the next stage, the researcher makes a presentation of the design results and adds features after getting input from the user. Interview data were analyzed in a structured manner through the coding, cleaning, transcript, and presentation stages of narrative data.

\section{RESULTS}

\section{A. This was using a research \& development method} $(R \& D)$ research design Identification of the patient's medical resume at PKU Muhammadiyah Bantul Hospital.

The author wants to find out whether there is an electronic medical resume at PKU Muhammadiyah Bantul Hospital and whether it has been implemented optimally.

Based on the three informants' answers, it can be concluded that the PKU Muhammadiyah Bantul Hospital has a discharge summary. The types of medical resumes available are manual and electronic, for electronic a discharge summary can be found on the hospital electronic medical records. A manual discharge summary is given to the patient upon discharge after the patient has been hospitalized.

\section{B. Requirements for User Interface Elements}

For data elements for the patient discharge summary user interface adjusts to the manual medical resume but with additions in several sections according to user needs. The addition referred to is the addition of SOAP (subject, object, assessment, planning), an ICD code for each disease diagnosis, procedure, and therapy.

\section{Redesign discharge summary.}

PKU Muhammadiyah Bantul Hospital allows the creation of a web-based patient discharge summary portal. It can improve patient information. However, there are several considerations to make the portal design easy for users to understand, such as not clicking too many clicks and being applied on the web.

\section{User interface design}

\section{1) User interface discharge summary logo}

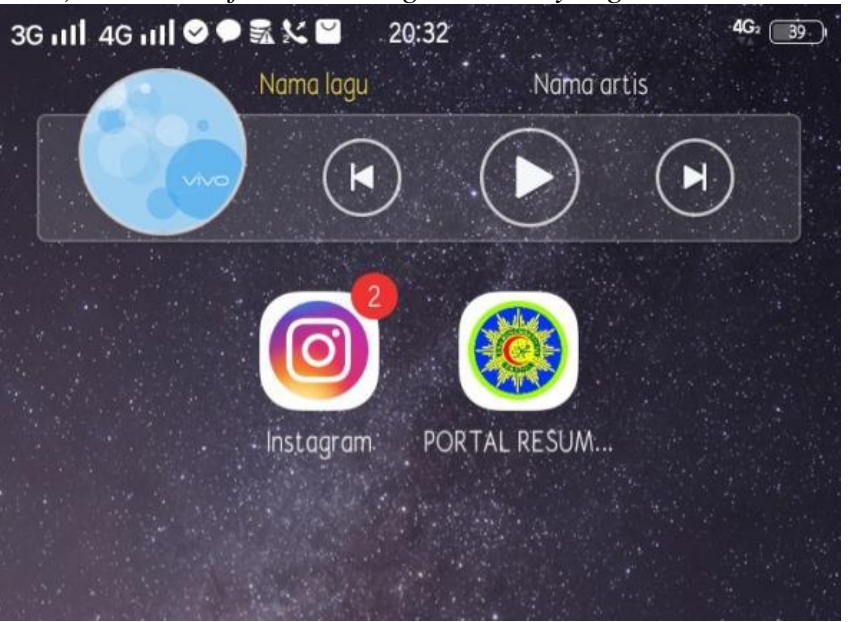

Fig. 2. Logo discharge summary portal

The discharge summary portal interface uses the PKU Muhammadiyah Bantul Hospital logo as an icon for the application. this logo indicated the apps have been installed. Patients will get a website link from the PKU Muhammadiyah Bantul hospital admin for download.

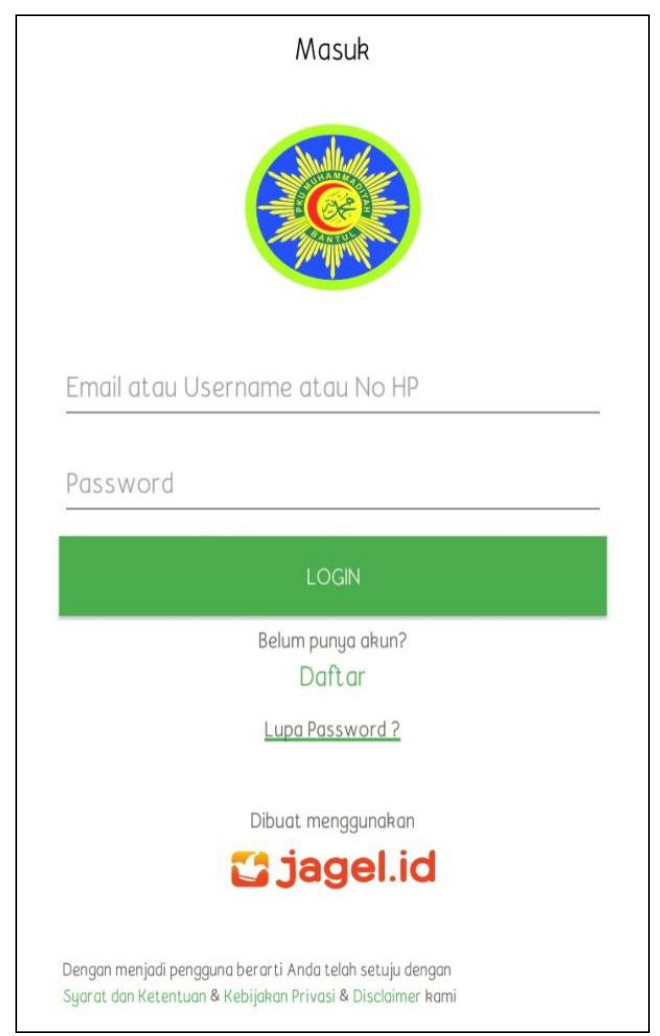

Fig. 3. Log in screen 
The main page is completed simply. To get a user ID, patients are required to register first on the register menu (Fig.4).

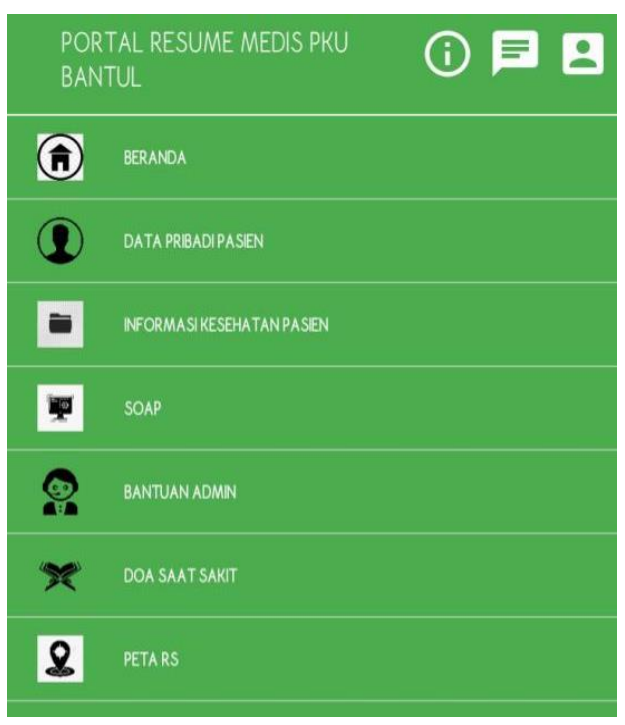

Fig. 4. Main page

The main page designed is simple. To get a user ID, patients are required to register first on the register menu. There is a settings menu to make changes to data, appearance, profile photos, and passwords. This portal available page for patient account (Fig. 5)

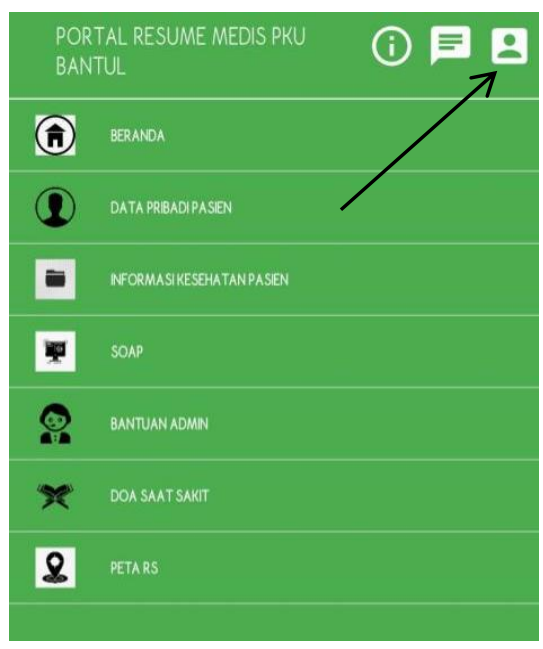

Fig. 5. Screen of patient account

\section{2) Dashbord page}

On the dashboard page, there is an "admin help" menu which contains the hospital admin's phone number if the patient needs it to obtain data or information related to his discharge summary. However, there is a chat menu with the admin which is directly listed in the upper right corner next to the "my account" menu. Patients can directly ask for anything related to their medical resume information to the hospital admin. Patients can also send pictures as attachments if needed. With the admin chat menu, it will be easier for patients to exchange information with the admin. However, if the patient experiences network or signal problems, the patient can open the admin help menu which lists the hospital admin's phone number (Fig. 6 and 7).

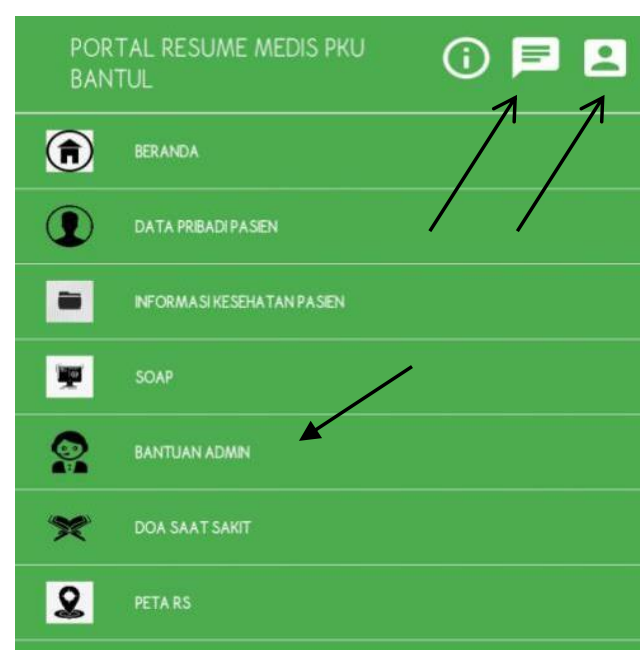

Fig. 6. Admin help menu

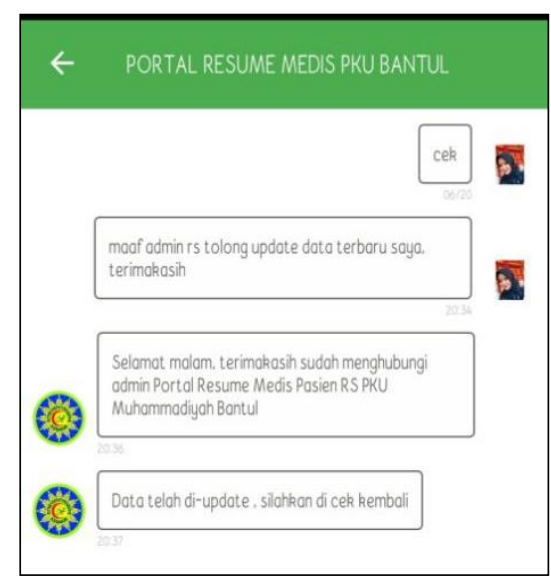

Fig. 7. Chat screen

\section{3) Discharge summary patient data}

This portal has a veranda menu as a form of welcome using Arabic and brief information related to a discharge summary (Fig. 8)

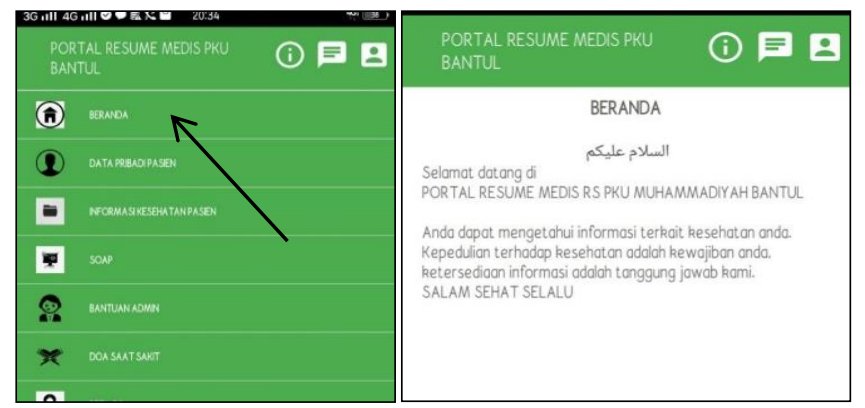

Fig. 8. Beranda menu

\section{4) Personal information}

When the patient presses the patient personal data menu, the patient will be shown in the next three menus, namely; patient personal data, allergy history, and other information. Of course the information contained in this patient's personal data has been integrated with the data contained in the PKU Muhammadiyah Bantul Hospital. Even though this menu is the patient's personal data, the patient cannot change the contents of the data contained therein by themselves. If there is data that is not suitable, the patient can reconfirm it to the hospital admin (Fig.9). 

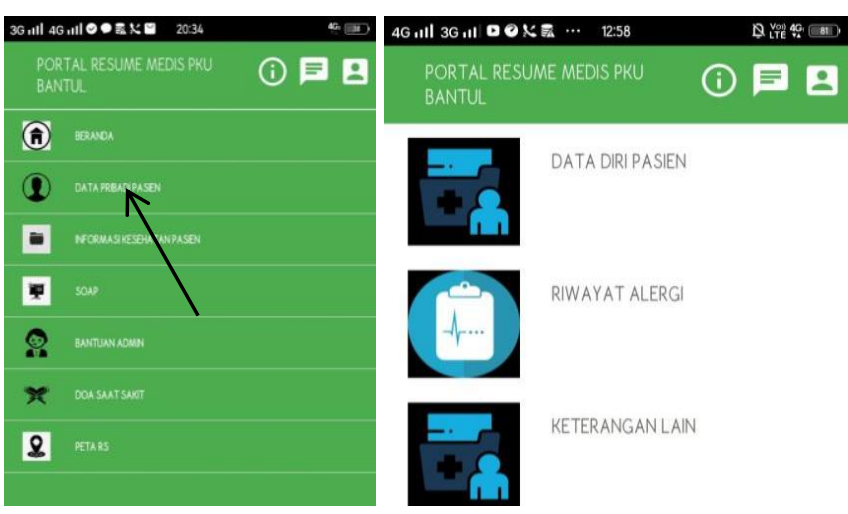

Fig. 9. Personal data

\section{5) Patient Information}

The dashboard display about patient information. Patients can see their health information that has been integrated with patient data listed in the PKU Muhammadiyah Bantul hospital information system consisting of vital sign information, admission complaints, diagnosis, therapy, treatment, and discharge conditions (Fig, 10- Fig. 18).

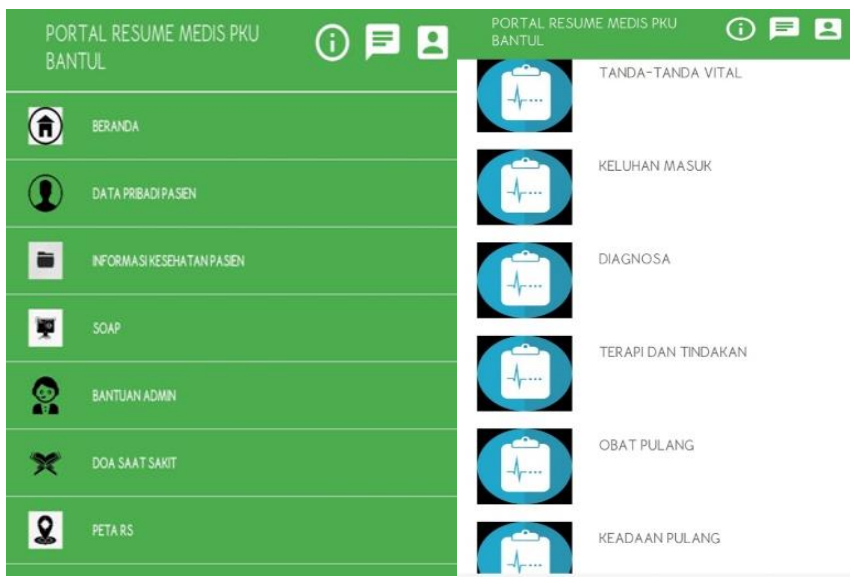

Fig. 10. Dashboard patient information

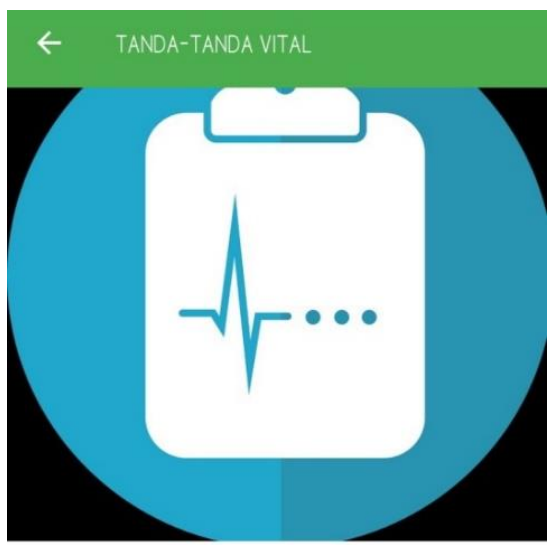

TANDA-TANDA VITAL

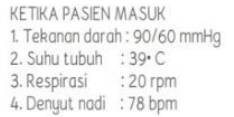

Fig. 11. Vital sign the doctor fills in the patient's vital signs during admission and after treatment

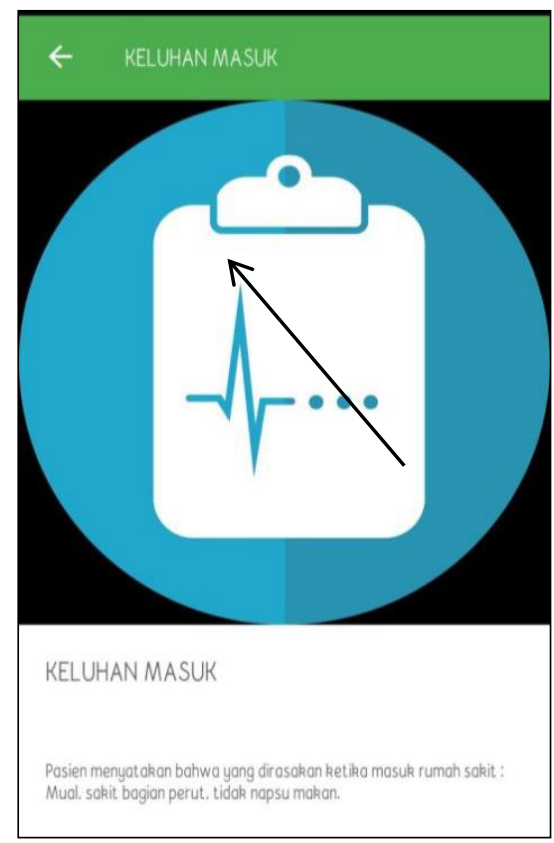

Fig. 12. ill-condition and history

Patients can access medical history and medication as a means of communication when visiting other hospitals. This portal also provides diagnostic information, of course this provides information on the history of the disease with coding diagnosis using ICD-10 (Fig.13)

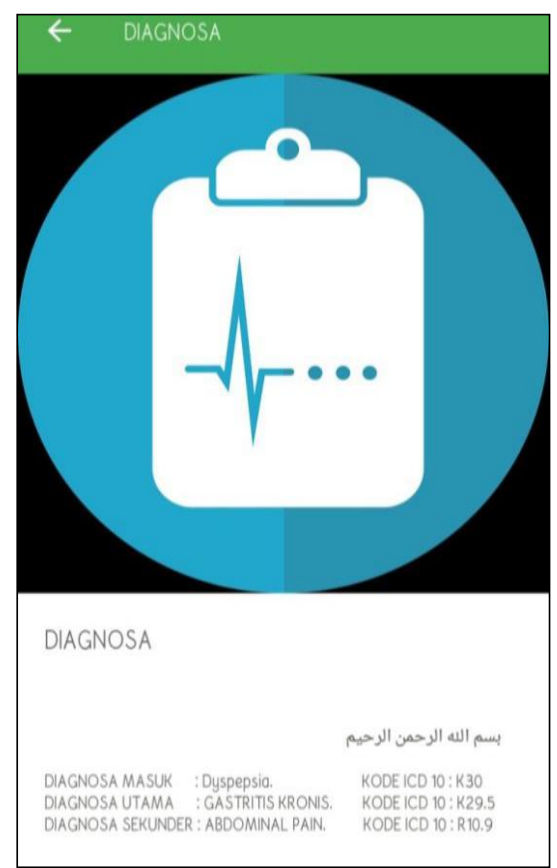

Fig. 13. Item diagnosis

Patients can access information on actions or treatments that have been received during treatment, by pressing the therapy and action menu (Fig. 14). other information the patient can access drugs that have been prescribed by the doctor (Fig. 15) 


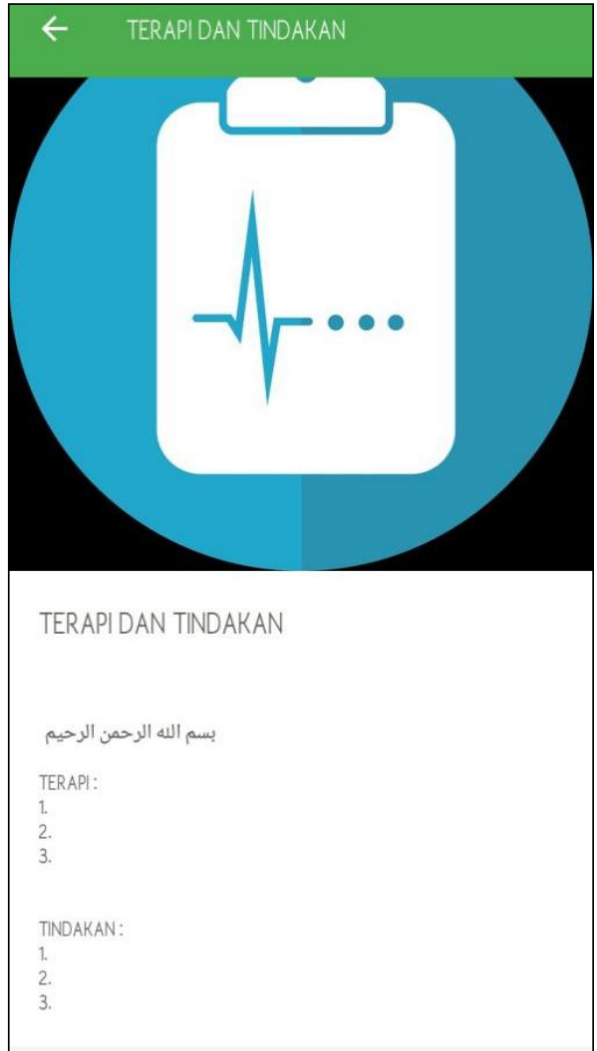

Fig. 14. Therapy and action menu

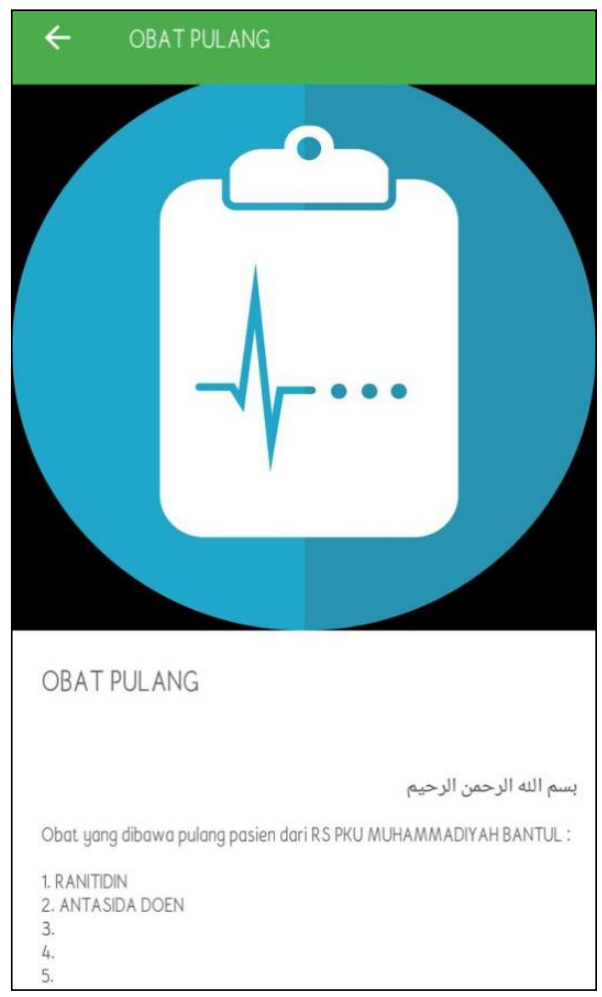

Fig. 15. Medical prescription

If the patient chooses the home state menu, the patient will know the situation when he goes home according to the information given by the hospital (Fig. 16)

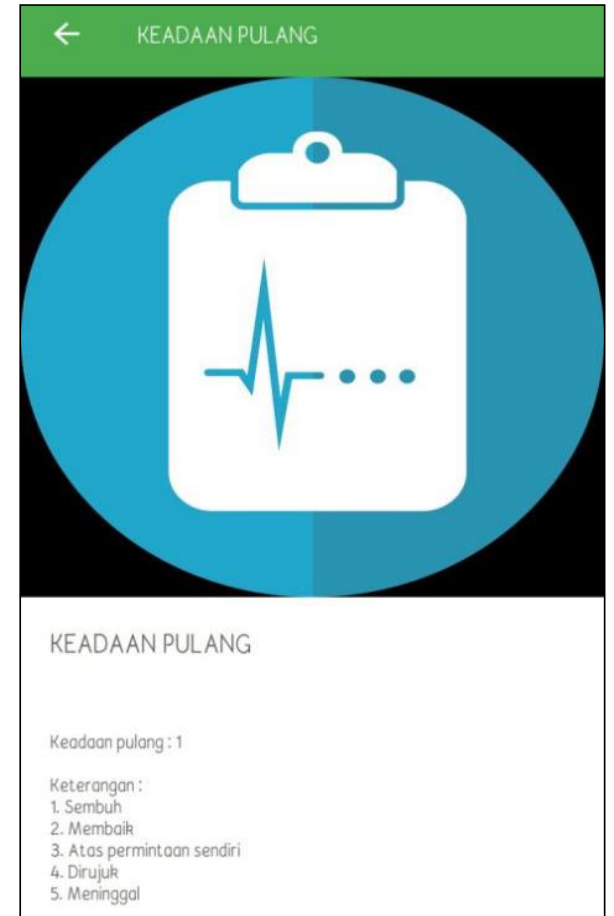

Fig. 16. Situation

If the patient selects the SOAP menu, the patient will see the treatment report data when the patient is admitted to the hospital. The data is filled in by the doctor after examining the patient when the patient is treated (Fig.17)

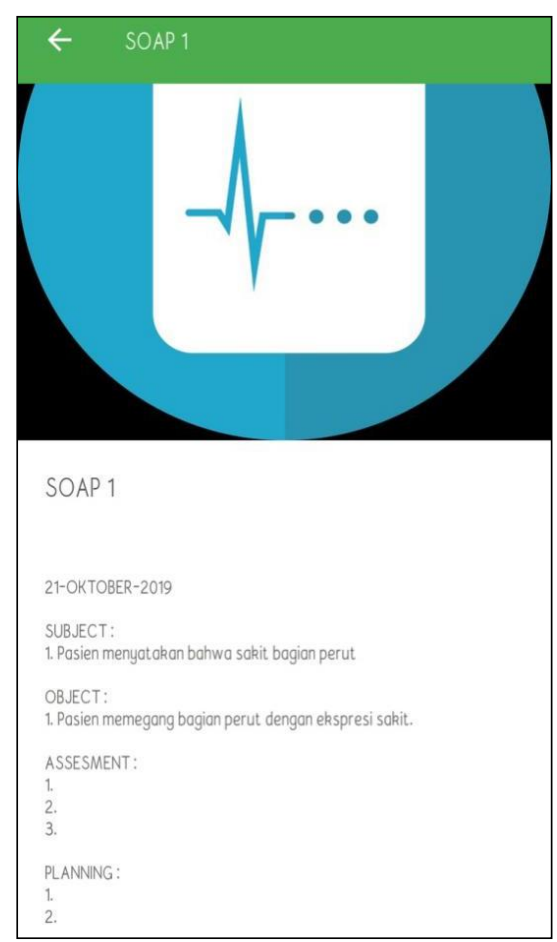

Fig. 17. SOAP menu

To support the patient's healing process, this portal provides a prayer menu for the purpose of supporting spiritual healing (Fig.18) 


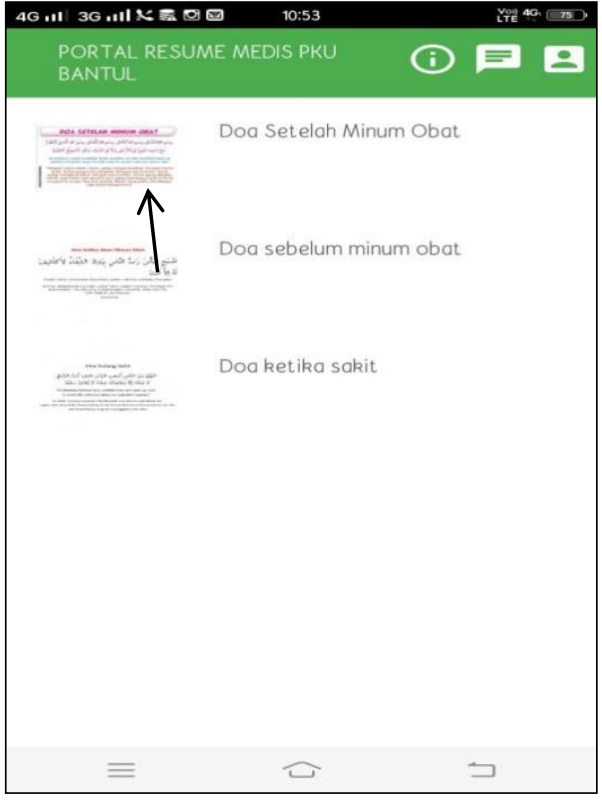

Fig. 18. Pray menu

\section{DISCUSSION}

\section{A. Identify the discharge summary}

The use of discharge summaries is still prioritized by manual over electronic. Electronic discharge summary can only be accessed by nurses and doctors in some polyclinics with limited data elements. A discharge summary is given to the patient on discharge. A Manual discharge summary will slow down service if the patient wants to access their health information, while the electronic one makes it easy for patients to access data at any time(1). The web-based discharge summary portal uses a link that is integrated with the hospital information system. A website is a specific computer location on the internet with a unique address called a URL (uniform resource locator), which consists of several linked web pages, which can contain text, images, sound, or video . Users can use the website via computer or mobile (2)(3).

Discharge summary also serves as a communication medium for health workers so that health workers know patient health information in an integrated manner between related units(4)(5). Communication is the center of interest or center of interest in situations of human behavior, to divert a message to the recipient with the aim of influencing certain behaviors and actions (6)(7).

\section{B. Requirements for User Interface Elements}

One of the most important factors in the preparation of the interface discharge summary, of course, the needs of users who refer to the data in the medical record are found at PKU Muhammadiyah Bantul Hospital. In terms of the user interface, there are several problems such as inconsistent design, lack of prevention and handling of problems, not achieving the ease of users in obtaining the information needed, and not achieving simplicity in visual design(8)(9).

The screen user interface design and the colors used in the menu and sub-menu Portal discharge summary is made simpler so that users are interested in the operating system(10)(11).

\section{Design interface}

Discharge summary design is made by maximizing data elements that remain complete and is expected to make users easy to understand and comfortable in use. Simple steps and an attractive design are also one of the attractions for users to feel comfortable operating a web-based patient medical resume portal. The importance of a design by following the user needed.

The purpose of the user interface design is to make it easier for users to work with computers so that they become more productive and enjoyable and effective as possible(12)(13)

\section{CONCLUSIONS}

The web-based patient discharge summary portal at PKU Muhammadiyah Bantul Hospital can increase the speed of service to patients who want their health information.

\section{ACKNOWLEDGMENT}

Our gratitude goes to all health practitioners, doctors and medical record officers at PKU Muhammadiyah Bantul Yogyakarta, Medical Records and Department of Clinical Information System, Faculty of Health Universitas Jenderal Achmad Yani Yogaykarta.

\section{REFERENCES}

[1] Awasighe Francis E, Veronica Chizoba G, Adesola O. Using Mobile Technology to Access Sexual and Reproductive Health Information and Services by Adolescent \& Young Persons: Findings from Nigeria. Univers J Public Heal. 2019;7(2):73-81.

[2] Vest JR, Kern LM, Silver MD, Kaushal R. The potential for community-based health information exchange systems to reduce hospital readmissions. 2014;1-6

[3] Setyorini T. Pengembangan Prototipe Sistem Informasi Manajemen Industri Rumah Tangga Pangan Berbasis Web Untuk Meningkatkan Pengawasan Keamanan Pangan Di Daerah Istimewa Yogyakarta. 2007

[4] World Health Organization. Electronic Health Record Manual for Developing Countries. Geneva; 2006. 1-78 p.

[5] Mehta RL, Baxendale B, Roth K, Caswell V, Le Jeune I, Hawkins J, et al. Assessing the impact of the introduction of an electronic hospital discharge system on the completeness and timeliness of discharge communication: A before and after study. BMC Health Serv Res. 2017;17(1):1-10.

[6] Sharda P, Das AK, Patel VL. Specifying design criteria for electronic medical record interface using cognitive framework. AMIA Annu Symp Proc. 2003;594-8.

[7] Lehnbom EC, Raban MZ, Walter SR, Richardson K, Westbrook JI. Do electronic discharge summaries contain more complete medication information? A retrospective analysis of paper versus electronic discharge summaries. 2014;43(3).

[8] Ong P, Gambatese M, Begier E, Zimmerman R, Soto A, Madsen A. Effect of cause-of-death training on agreement between hospital discharge diagnoses and cause of death reported, inpatient hospital deaths, New York city, 2008-2010. Prev Chronic Dis. 2015;12(1).

[9] Kuqi K, Eveleigh T, Holzer T, Sarkani S, Levin JE, Crowley RS. Design of electronic medical record user interfaces: A matrix-based method for improving usability. J Healthc Eng. 2013;4(3):427-51.

[10] Elgendi M, Howard N, Lovell N, Hons BE. A Six-Step Framework on Biomedical Signal Analysis for Tackling Noncommunicable Diseases : Current and Future Perspectives Corresponding Author : 2016;1:1-15.

[11] Systems CD. Clinical Decision-Support Systems. :698-736.

[12] Saitwal H, Feng X, Walji M, Patel V, Zhang J. Assessing performance of an Electronic Health Record (EHR) using Cognitive Task Analysis. Int J Med Inform [Internet]. 2010;79(7):501-6. Available from: http://dx.doi.org/10.1016/j.ijmedinf.2010.04.001

[13] Schnall R, Rojas M, Bakken S, Iii WB, Carballo- A, Carry M, et al. A user-centered model for designing consumer mobile health application (apps). J Biomed Inf. 2017;60:243-51. 